\title{
The utility of rebound tonometer in late elderly subjects
}

\author{
This article was published in the following Dove Press journal: \\ Clinical Interventions in Aging \\ 22 January 2014 \\ Number of times this article has been viewed
}

\author{
Rei Sakata ${ }^{1,2}$ \\ Jiro Numaga' \\ 'Tokyo Metropolitan Geriatric \\ Hospital, Tokyo, Japan; ${ }^{2}$ Department \\ of Ophthalmology, University of \\ Tokyo, Graduate School of \\ Medicine, Tokyo, Japan
}

Background: To compare intraocular pressure (IOP) readings using the Icare rebound tonometer (RBT) versus the Goldmann applanation tonometer (GAT) in late elderly (aged 75 years or older) subjects with or without glaucoma, and to evaluate the influence of central corneal thickness (CCT) on IOP readings.

Methods: The IOP measurements were obtained using the RBT and GAT, and CCT was measured using a specular-type microscope. Bland-Altman analysis was used to assess the clinical agreement between the two instruments. The influence of CCT adjusted for age on IOP readings was analyzed by multiple linear regression analysis.

Results: This study included 58 eyes of 29 normal subjects and 54 eyes of 28 glaucoma patients. The mean age was $80.7 \pm 4.3$ years (normal subjects) and $83.1 \pm 5.1$ years (glaucoma patients). The mean IOP readings were $13.6 \pm 3.5 \mathrm{mmHg}$ and $13.2 \pm 2.8 \mathrm{mmHg}$ (using the RBT and GAT, respectively) for normal subjects, and13.6 $\pm 3.3 \mathrm{mmHg}$ and $13.5 \pm 2.9 \mathrm{mmHg}$ for glaucoma patients. The $95 \%$ confidence interval of the differences between the two instruments was -3.3 to $4.0 \mathrm{mmHg}$ for normal subjects and -2.9 to $1.6 \mathrm{mmHg}$ for glaucoma patients. The IOP readings by two instruments were significantly correlated with CCT in eyes with glaucoma (for the RBT, $\beta=0.036$ and $P=0.002$, and for the GAT, $\beta=0.021$ and $P=0.033$ ) but not in normal eyes.

Conclusion: IOP readings measured using the RBT and GAT showed within the allowable range in the late elderly subjects with or without glaucoma. Eyes with glaucoma were correlated closely with CCT using each instrument.

Keywords: rebound tonometer, Goldmann applanation tonometer, late elderly, central corneal thickness

\section{Introduction}

Previous randomized clinical trials have established the efficacy of reducing intraocular pressure (IOP) in patients with glaucoma, ${ }^{1-5}$ confirming that IOP management plays a central role in preventing further progression of glaucomatous optic neuropathy. ${ }^{6-8}$ Although the Goldmann applanation tonometer (GAT) (Haag Streit, Koeniz, Switzerland) has been recognized as the gold standard tonometer up to the present date, ${ }^{9}$ some limitations associated with the instrument have been reported, including the influence of central corneal thickness (CCT) on IOP readings, ${ }^{10-12}$ the necessity of topical anesthesia, ${ }^{13}$ the requirement of a certain amount of experience in measurement, the nonutility for babies or bedridden patients, and the risk of secondary infection via exposure to the cornea. ${ }^{14}$

The Icare $^{\circledR}$ rebound tonometer (RBT) (Icare TA01i, Tiolat, Finland) is a compact, handheld contact tonometer that does not require topical anesthesia. ${ }^{15}$ 
Consequently, because of its simplicity and noninvasive nature, the RBT is used widely in children. ${ }^{16-18}$ However, the agreement between RBT and GAT readings in children is debated, and more data are necessary to assess the differences, including data at various IOPs. ${ }^{19,20}$ One reason is that the RBT might be affected by IOP. ${ }^{21,22}$ Moreover, it is necessary to investigate the effect of CCT on the RBT in infants and young children. In recent years, various RBT models have been marketed. It is now possible for patients to measure their own IOP, ${ }^{23}$ alternatively, it can be measured in the clinic in positions other than horizontal (ie, spine or decubitus positions). ${ }^{24}$

Studies comparing IOP measured in normal eyes and in those with glaucoma, using the RBT (Icare) and GAT, reported that the IOP readings tended to be higher using the RBT than the GAT. ${ }^{21,25-41}$ However, one study reported higher IOP readings using the GAT. ${ }^{42}$ Like the GAT, the RBT has also been reported to be influenced by corneal properties. ${ }^{33,36,43-45}$ Both RBT and GAT overestimate IOP in eyes with a thicker cornea, and vice versa.

To date, no studies have projected to compare IOP readings measured by both instruments in late elderly (aged 75 years or older) subjects. The mean age of subjects in previous studies ranged not more than 72 years. As the average life expectancy in society continues to increase, greater numbers of geriatric patients with difficult-to-measure IOP by GAT are expected because of their ocular or physical problems; therefore, occasions for using handheld tonometers such as RBT will increase much more in upcoming medical practice.

The aim of this study was to evaluate the utility of the RBT by comparing it with the GAT in late elderly subjects with or without glaucoma, and to investigate a correlation between IOP readings and CCT.

\section{Materials and methods}

Late elderly Japanese normal subjects and glaucoma patients, including those undergoing medical treatment, were recruited at the Tokyo Metropolitan Geriatric Hospital, Tokyo, Japan. Glaucoma was defined according to the presence of glaucomatous optic nerve head damage with corresponding visual field damage. Eyes were excluded in patients with ocular surface disorders (eg pterygium), which prevent IOP measurements.

IOP measurements were taken by one well-trained ophthalmologist at a routine outpatient clinic. To minimize the possible reduction in IOP caused by eye oppression from contact with the tonometer, ${ }^{46}$ IOP measurements were taken by the RBT (Icare) first. Two sequential IOP readings (the right eye first) were measured. For the RBT, the mean of six consecutive measurements after removing the highest and lowest measurements were displayed with a quality indicator $(\mathrm{P})$. IOP readings were accepted when the horizontal line (standard error; standard deviation) showed in the lowermost part in the display. Next, after applying one drop of topical oxybuprocaine hydrochloride anesthesia $(0.4 \%$ Benoxil $^{\circledR}$, Santen, Tokyo, Japan), we used the calibrated GAT connected to the slit-lamp microscopy. Also, two sequential IOP readings (the right eye first) were measured. The average IOPs were used for analysis. CCT was measured using a specular-type microscope (Noncon Robo, Konan Medical, Nishinomiya, Japan) on the same visiting day.

We are planning a study of a continuous response variable from matched pairs of study subjects. Preliminary data indicate that the difference in the response of matched pairs is normally distributed, with a standard deviation of $2.5 \mathrm{mmHg}$. If the true difference in the mean response of matched pairs is $1 \mathrm{mmHg}$, we will need to study 58 pairs of subjects to be able to reject the null hypothesis that this response difference is zero with a probability (power) of 0.85 . The type I error probability associated with this test of this null hypothesis is 0.05 . The Bland-Altman plot ${ }^{47}$ was used to evaluate the differences in IOP readings. The difference between IOP measurements was plotted against the mean. The correlation between the IOP obtained using the two instruments and the CCT was analyzed by multiple linear regression analysis adjusted for age.

In normal subjects or glaucoma patients, we used the following equation:

$$
\mathrm{y}(\mathrm{IOP})=\beta_{0}+\beta_{1} \times \mathrm{CCT}+\beta_{2} \times \text { age }
$$

where $\beta_{0}$ is intercept and $\beta_{1}$ and $\beta_{2}$ are regression coefficients for CCT and age, respectively. Regarding IOP, we analyzed RBT and GAT separately. Two-tailed values of $P<0.05$ indicated statistical significance. All analyses were performed using JMP version 9.0.2 statistical software (SAS Institute Inc., Cary, NC, USA).

This study was conducted in accordance with the Declaration of Helsinki, and the study protocol was approved by the Ethics Committee of the Tokyo Metropolitan Geriatric Hospital. Informed consent was obtained from participants.

\section{Results}

A total of 29 normal subjects (58 eyes) and 28 glaucoma patients (54 eyes) completed this study with no ocular/ systemic side effects. The results for 54 glaucoma eyes were as follows: 43 eyes were normal tension glaucoma (34 eyes 
with medications, nine eyes without medications), eight eyes were primary open-angle glaucoma (eight eyes with medications), one eye was secondary open-angle glaucoma (with medications), and two eyes were without glaucomatous optic neuropathy.

\section{IOP readings and consistency of the two instruments}

The mean IOP readings used by the RBT and GAT were 13.6 $\pm 3.5 \mathrm{mmHg}$ and $13.2 \pm 2.8 \mathrm{mmHg}$ (mean difference $0.34 \mathrm{mmHg}, P=0.22$ ) in normal subjects, and $13.6 \pm 3.3 \mathrm{mmHg}$ and $13.5 \pm 2.9 \mathrm{mmHg}$ (mean difference $0.14 \mathrm{mmHg}, P=0.53$ ) in glaucoma patients. The $95 \%$ limits of agreement between the RBT and the GAT ranged from $-3.3 \mathrm{mmHg}$ to $4.0 \mathrm{mmHg}$ in normal subjects and from $-2.0 \mathrm{mmHg}$ to $1.6 \mathrm{mmHg}$ in glaucoma patients (Figures 1 and 2). Eyes with differences within $\pm 1 \mathrm{mmHg}$ measured by both instruments were $23 / 58(40 \%)$ for normal subjects and 24/54 (44\%) for glaucoma patients.

\section{CCT influence on IOP readings}

Mean CCT was 561 $\pm 38 \mu \mathrm{m}$ (range 465-632 $\mu \mathrm{m}$; median $567 \mu \mathrm{m}$ ) for normal subjects and $549 \pm 44 \mu \mathrm{m}$ (range; 439-624 $\mu \mathrm{m}$; median $546 \mu \mathrm{m}$ ) for glaucoma patients. In multiple linear regression analyses adjusted for age, IOP reading for glaucoma eyes was correlated positively with
CCT (for the RBT, $\beta=0.036$ and $P=0.002$ and for the GAT, $\beta=0.021$ and $P=0.033$ ), whereas no correlation was found in normal eyes (for the RBT, $\beta=0.005$ and $P=0.76$ and for the GAT, $\beta=0.015$ and $P=0.27$ ) (Table 1).

\section{Discussion}

The RBT is a handheld tonometer that does not require topical anesthesia, which has been proved to be useful in animal/human studies. ${ }^{42,48}$ Although many previous comparative studies have investigated its usability, ${ }^{21,25-41}$ our study included patients with the greatest mean age ( $81.9 \pm 4.8$ years, overall).

Previous studies demonstrated that the RBT instrument resulted in a slight overestimation (mean $0.9 \mathrm{mmHg}$ ) of IOP measurement in eyes in the presence or absence of glaucoma compared with the GAT. ${ }^{40}$ In contrast, Kontiola et $\mathrm{al}^{42}$ demonstrated that IOP readings using the GAT were higher than those using the RBT (estimated equation $\mathrm{RBT}=0.9 \times \mathrm{GAT}-4.8 \mathrm{mmHg}$ ). However, it should be considered that the RBT used in that study was a prototype; moreover, the background of the enrolled patients was unclear. For this reason, it may be too hard to make an assertion about the homologous comparison between the RBT and the GAT.

In our study, the difference in IOP readings using the two instruments was $0.34 \mathrm{mmHg}$ for normal subjects and $0.14 \mathrm{mmHg}$ for glaucoma patients. These results would

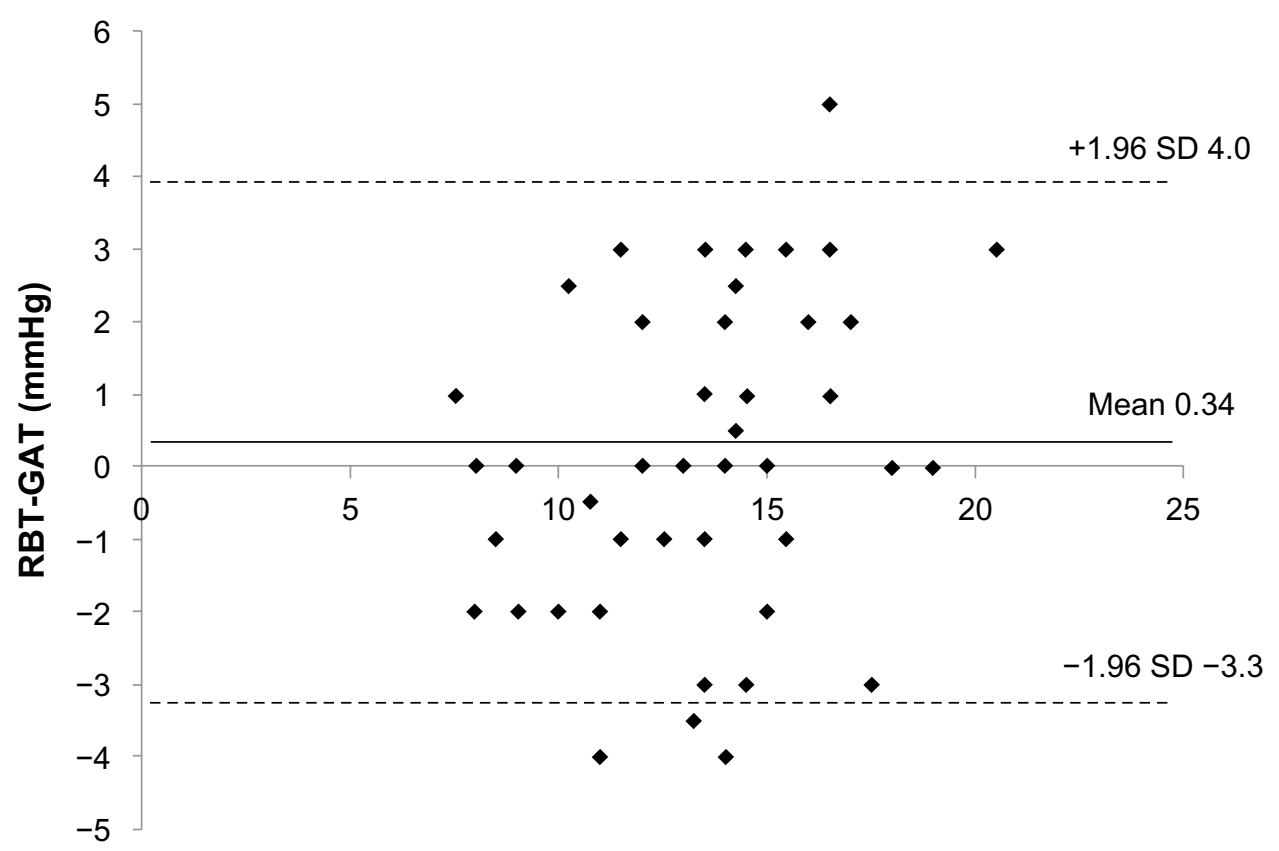

Average of RBT and GAT ( $\mathrm{mmHg}$ )

Figure I Bland-Altmann plot of the rebound tonometer (RBT) readings minus the Goldmann applanation tonometer (GAT) readings (mmHg) versus the mean of both in normal subjects. 


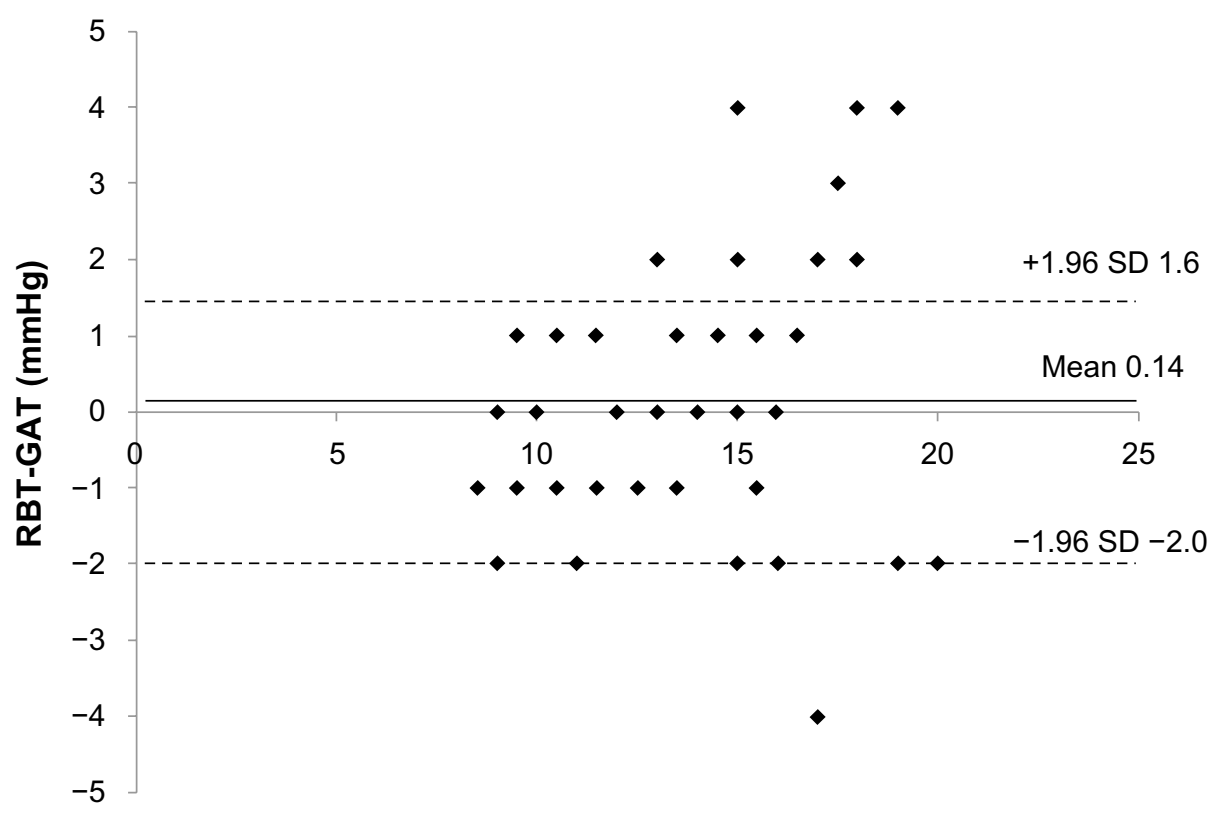

Average of RBT and GAT $(\mathrm{mmHg})$

Figure 2 Bland-Altmann plot of the rebound tonometer (RBT) readings minus the Goldmann applanation tonometer (GAT) readings (mmHg) versus the mean of both in glaucoma patients.

demonstrate that IOP measurements were not consistently overestimated or underestimated using the RBT compared with the GAT, suggesting that the RBT is useful and practicable compared with the GAT, even in late elderly subjects. The width of $95 \%$ limit of agreement was widely distributed $(-4.3 \mathrm{mmHg}$ to $6.1 \mathrm{mmHg})$ in a systematic review. ${ }^{40}$ Although a direct comparison cannot be made, our study showed a $95 \%$ limit of agreement within $-3.3 \mathrm{mmHg}$ to $4.0 \mathrm{mmHg}$ (overall subjects), which was in the allowance range among the previous studies.

CCT is known to influence IOP measurements when using the contact applanation tonometer. ${ }^{10-12,33,36,43-45}$ The IOP change could be somewhat overestimated in eyes with a thicker cornea. One study that investigated the influence of corneal properties (CCT, corneal hysteresis $[\mathrm{CH}]$, and corneal resistance factor $[\mathrm{CRF}]$ ) on the RBT revealed that RBT measurements were affected by $\mathrm{CH}$ and CRF but not

Table I Multivariable analysis of factors associated with RBTIOP and GAT-IOP in normal subjects and glaucoma patients ${ }^{\mathrm{a}}$

\begin{tabular}{llllll}
\hline & \multicolumn{2}{l}{ Normal subjects } & & \multicolumn{2}{l}{ Glaucoma patients } \\
\cline { 2 - 3 } \cline { 5 - 6 } & RBT-IOP & GAT-IOP & & RBT-IOP & GAT-IOP \\
\hline Age, y & $0.14(0.43)$ & $0.076(0.57)$ & & $0.016(0.87)$ & $0.011(0.90)$ \\
CCT, $\mu \mathrm{m}$ & $0.005(0.76)$ & $0.015(0.27)$ & & $0.036(0.002)$ & $0.021(0.034)$ \\
\hline
\end{tabular}

Note: ${ }^{a}$ Data are shown as regression coefficient ( $P$-value).

Abbreviations: CCT, central corneal thickness; GAT-IOP, Goldmann applanation tonometer intraocular pressure; RBT-IOP, rebound tonometer intraocular pressure; y, years. by CCT in multiple regression analysis. ${ }^{44}$ However, it can be difficult to measure the $\mathrm{CH}$ or $\mathrm{CRF}$ in the outpatient clinic, and the CCT measurement is a classic and convenient method for measuring corneal properties. Indeed, the IOP was positively correlated with the CCT in univariate analysis in the same study $(r=0.5, P<0.01){ }^{44}$ Wong et a ${ }^{49}$ had reported that CCT did not correlate with IOP after being adjusted for age in elderly subjects aged over 60 years, although the demographic data of age and population are different from ours. Our result showed a positive correlation between CCT and the IOP readings in glaucoma eyes but not in normal eyes. The fact that correlation with CCT was observed in glaucoma eyes by each instrument reconfirms the importance of CCT measurements in glaucoma management.

Although IOP shows a trend toward a subtle inverted U-shape relationship with increasing age, ${ }^{49}$ the prevalence of glaucoma increases in proportion to increasing age..$^{50}$ The main advantage of the handheld tonometer is its utility in assessing some geriatric patients who cannot transfer to an examination table due to a physical disability or a wheelchair, or those with ocular disability such as blepharospasm. Although other portable devices apart from RBT may also be serviceable: eg, the Tono-Pen ${ }^{\circledR}$ (Tono-Pen XL, Reichert, Inc., Depew, NY, USA), Perkins tonometer (Haag-Streit USA, OH, USA), or pneumatonometer, (PTG, Reichert, Inc., Depew, NY, USA), they require calibration adjustment and 
topical anesthesia at the time of measurement. Use of these instruments should be considered in light of the advantages and disadvantages of each.

Because most participants in this study were normal subjects or patients with normal tension glaucoma including treatment, the mean IOP difference could not help but be small. The difference between the RBT and the GAT is reported to become more obvious in cases with high IOP values. ${ }^{21}$ Future studies should increase the number and include subjects with a varied range of IOP. Furthermore, because other factors related to IOP (such as blood pressure, refraction, and body mass index) are reported, ${ }^{51-53}$ we need to consider the result from various orientations in the future.

\section{Conclusion}

We evaluated the utility of the RBT in terms of comparing with the GAT in late elderly subjects. A slight difference in IOP readings appeared to be within the allowable range. Careful attention is required when interpreting IOP readings in glaucoma eyes, because both instruments were positively correlated with the CCT. Our findings might suggest the utility of this handheld tonometer in the late elderly, especially for those in whom it may be difficult to perform measurements using the GAT.

\section{Disclosure}

Authors declare no conflicts of interest in this work. This research received no specific grant from any funding agency in the public, commercial, or not-for-profit sectors.

\section{References}

1. Collaborative Normal-Tension Glaucoma Study Group. Comparison of glaucomatous progression between untreated patients with normaltension glaucoma and patients with therapeutically reduced intraocular pressures. Am J Ophthalmol. 1998;126(4):487-497.

2. The Advanced Glaucoma Intervention Study (AGIS): 7. The relationship between control of intraocular pressure and visual field deterioration. Am J Ophthalmol. 2000;130(4):429-440.

3. Kass MA, Heuer DK, Higginbotham EJ, et al. The Ocular Hypertension Treatment Study: a randomized trial determines that topical ocular hypotensive medication delays or prevents the onset of primary openangle glaucoma. Arch Ophthalmol. 2002;120(6):701-713; discussion 829-730.

4. Leske MC, Heijl A, Hussein M, Bengtsson B, Hyman L, Komaroff E. Factors for glaucoma progression and the effect of treatment: the early manifest glaucoma trial. Arch Ophthalmol. 2003;121(1):48-56.

5. Miglior S, Zeyen T, Pfeiffer N, Cunha-Vaz J, Torri V, Adamsons I. Results of the European Glaucoma Prevention Study. Ophthalmology. 2005;112(3):366-375.

6. Leske MC, Heijl A, Hyman L, Bengtsson B, Dong L, Yang Z. Predictors of long-term progression in the early manifest glaucoma trial. Ophthalmology. 2007;114(11):1965-1972.
7. Allingham RR, Damji KF, Freedman SF, Mori SE, Rhee DJ, Shields MB Shields'Textbook of Glaucoma. 6th ed. Philadelphia, PA: Lippinscott Williams \& Wilkins; 2010.

8. European Glaucoma Society. Terminology and Guidelines for Glaucoma. 3rd ed. Savona, Italy: European Glaucoma Society; 2010.

9. Goldmann H, Schmidt T. Applanation tonometry. Ophthalmologica. 1957;134(4):221-242.

10. Ehlers N, Hansen FK, Aasved H. Biometric correlations of corneal thickness. Acta Ophthalmol (Copenh). 1975;53(4):652-659.

11. Whitacre MM, Stein R. Sources of error with use of Goldmann-type tonometers. Surv Ophthalmol. 1993;38(1):1-30.

12. Doughty MJ, Zaman ML. Human corneal thickness and its impact on intraocular pressure measures: a review and meta-analysis approach. Surv Ophthalmol. 2000;44(5):367-408.

13. Baudouin C, Gastaud P. Influence of topical anesthesia on tonometric values of intraocular pressure. Ophthalmologica. 1994;208(6):309-313.

14. Walia JS, Chronister CL. Possible iatrogenic transmission of Creutzfeldt-Jakob disease via tonometer tips: a review of the literature. Optometry. 2001;72(10):649-652.

15. Dekking HM, Coster HD. Dynamic tonometry. Ophthalmologica. 1967;154(1):59-74.

16. Flemmons MS, Hsiao YC, Dzau J, Asrani S, Jones S, Freedman SF. Icare rebound tonometry in children with known and suspected glaucoma. J AAPOS. 2011;15(2):153-157.

17. Lundvall A, Svedberg H, Chen E. Application of the ICare rebound tonometer in healthy infants. J Glaucoma. 2011;20(1):7-9.

18. Grigorian F, Grigorian AP, Olitsky SE. The use of the ICare tonometer reduced the need for anesthesia to measure intraocular pressure in children. J AAPOS. 2012;16(6):508-510.

19. Lambert SR, Melia M, Buffenn AN, Chiang MF, Simpson JL, Yang MB. Rebound tonometry in children: a report by the American Academy of Ophthalmology. Ophthalmology. 2013;120(4):e21-e27.

20. Dahlmann-Noor AH, Puertas R, Tabasa-Lim S, et al. Comparison of handheld rebound tonometry with Goldmann applanation tonometry in children with glaucoma: a cohort study. BMJ Open. 2013;3(4):pii:e001788.

21. Munkwitz S, Elkarmouty A, Hoffmann EM, Pfeiffer N, Thieme H. Comparison of the ICare rebound tonometer and the Goldmann applanation tonometer over a wide IOP range. Graefes Arch Clin Exp Ophthalmol. 2008;246(6):875-879.

22. Martinez-de-la-Casa JM, Garcia-Feijoo J, Saenz-Frances F, et al. Comparison of rebound tonometer and Goldmann handheld applanation tonometer in congenital glaucoma. J Glaucoma. 2009;18(1):49-52.

23. Sakamoto M, Kanamori A, Fujihara M, Yamada Y, Nakamura M, Negi A. Assessment of IcareONE rebound tonometer for self-measuring intraocular pressure. Acta Ophthalmol. Epub April 16, 2013.

24. Kim HS, Park KH, Jeoung JW. Can we measure the intraocular pressure when the eyeball is against the pillow in the lateral decubitus position? Acta Ophthalmol. 2013;91(7):e502-e505.

25. Martinez-de-la-Casa JM, Garcia-Feijoo J, Castillo A, Garcia-Sanchez J. Reproducibility and clinical evaluation of rebound tonometry. Invest Ophthalmol Vis Sci. 2005;46(12):4578-4580.

26. van der Jagt LH, Jansonius NM. Three portable tonometers, the TGDc-01, the ICare and the Tonopen XL, compared with each other and with Goldmann applanation tonometry. Ophthalmic Physiol Opt. 2005;25(5):429-435.

27. Fernandes P, Diaz-Rey JA, Queiros A, Gonzalez-Meijome JM, Jorge J. Comparison of the ICare rebound tonometer with the Goldmann tonometer in a normal population. Ophthalmic Physiol Opt. 2005;25(5): 436-440.

28. Martinez-de-la-Casa JM, Garcia-Feijoo J, Vico E, et al. Effect of corneal thickness on dynamic contour, rebound, and Goldmann tonometry. Ophthalmology. 2006;113(12):2156-2162.

29. Iliev ME, Goldblum D, Katsoulis K, Amstutz C, Frueh B. Comparison of rebound tonometry with Goldmann applanation tonometry and correlation with central corneal thickness. Br J Ophthalmol. 2006;90(7): 833-835. 
30. Nakamura M, Darhad U, Tatsumi Y, et al. Agreement of rebound tonometer in measuring intraocular pressure with three types of applanation tonometers. Am J Ophthalmol. 2006;142(2):332-334.

31. Davies LN, Bartlett H, Mallen EA, Wolffsohn JS. Clinical evaluation of rebound tonometer. Acta Ophthalmol Scand. 2006;84(2):206-209.

32. Brusini P, Salvetat ML, Zeppieri M, Tosoni C, Parisi L. Comparison of ICare tonometer with Goldmann applanation tonometer in glaucoma patients. J Glaucoma. 2006;15(3):213-217.

33. Sahin A, Niyaz L, Yildirim N. Comparison of the rebound tonometer with the Goldmann applanation tonometer in glaucoma patients. Clin Experiment Ophthalmol. 2007;35(4):335-339.

34. Abraham LM, Epasinghe NC, Selva D, Casson R. Comparison of the ICare rebound tonometer with the Goldmann applanation tonometer by experienced and inexperienced tonometrists. Eye (Lond). 2008;22(4): 503-506.

35. Johannesson G, Hallberg P, Eklund A, Linden C. Pascal, ICare and Goldmann applanation tonometry: a comparative study. Acta Ophthalmol. 2008;86(6):614-621.

36. Pakrou N, Gray T, Mills R, Landers J, Craig J. Clinical comparison of the Icare tonometer and Goldmann applanation tonometry. J Glaucoma. 2008;17(1):43-47.

37. Rehnman JB, Martin L. Comparison of rebound and applanation tonometry in the management of patients treated for glaucoma or ocular hypertension. Ophthalmic Physiol Opt. 2008;28(4):382-386.

38. Poostchi A, Mitchell R, Nicholas S, Purdie G, Wells A. The ICare rebound tonometer: comparisons with Goldmann tonometry, and influence of central corneal thickness. Clin Experiment Ophthalmol. 2009;37(7):687-691.

39. Martinez-de-la-Casa JM, Jimenez-Santos M, Saenz-Frances F, et al. Performance of the rebound, noncontact and Goldmann applanation tonometers in routine clinical practice. Acta Ophthalmol. 2011;89(7): 676-680.

40. Cook JA, Botello AP, Elders A, et al. Systematic review of the agreement of tonometers with Goldmann applanation tonometry. Ophthalmology. 2012;119(8):1552-1557.

41. Vincent SJ, Vincent RA, Shields D, Lee GA. Comparison of intraocular pressure measurement between rebound, non-contact and Goldmann applanation tonometry in treated glaucoma patients. Clin Experiment Ophthalmol. 2012;40(4):e163-e170.
42. Kontiola AI. A new induction-based impact method for measuring intraocular pressure. Acta Ophthalmol Scand. 2000;78(2):142-145.

43. Sahin A, Basmak H, Yildirim N. The influence of central corneal thickness and corneal curvature on intraocular pressure measured by tono-pen and rebound tonometer in children. J Glaucoma. 2008;17(1): 57-61.

44. Chui WS, Lam A, Chen D, Chiu R. The influence of corneal properties on rebound tonometry. Ophthalmology. 2008;115(1):80-84.

45. Rao A, Kumar M, B P, Varshney G. Relationship of central corneal thickness and intraocular pressure by ICare rebound tonometer. J Glaucoma. Epub December 3, 2012.

46. Schreiber W, Vorwerk CK, Langenbucher A, Behrens-Baumann W, Viestenz A. A comparison of rebound tonometry (ICare) with TonoPenXL and Goldmann applanation tonometry. Ophthalmologe. 2007;104(4):299-304.

47. Bland JM, Altman DG. Comparing methods of measurement: why plotting difference against standard method is misleading. Lancet. 1995;346(8982):1085-1087.

48. Kontiola A. A new electromechanical method for measuring intraocular pressure. Doc Ophthalmol. 1996;93(3):265-276.

49. Wong TT, Wong TY, Foster PJ, Crowston JG, Fong CW, Aung T. The relationship of intraocular pressure with age, systolic blood pressure, and central corneal thickness in an Asian population. Invest Ophthalmol Vis Sci. 2009;50(9):4097-4102.

50. Iwase A, Suzuki Y, Araie M, et al. The prevalence of primary open-angle glaucoma in Japanese: the Tajimi Study. Ophthalmology. 2004;111(9): 1641-1648.

51. Kawase K, Tomidokoro A, Araie M, Iwase A, Yamamoto T. Ocular and systemic factors related to intraocular pressure in Japanese adults: the Tajimi study. Br J Ophthalmol. 2008;92(9):1175-1179.

52. Tomoyose E, Higa A, Sakai H, et al. Intraocular pressure and related systemic and ocular biometric factors in a population-based study in Japan: the Kumejima study. Am J Ophthalmol. 2010;150(2): 279-286.

53. Avitabile T, Longo A, Rocca D, Amato R, Gagliano C, Castaing M. The influence of refractive errors on IOP measurement by rebound tonometry (ICare) and Goldmann applanation tonometry. Graefes Arch Clin Exp Ophthalmol. 2010;248(4):585-591.
Clinical Interventions in Aging

\section{Publish your work in this journal}

Clinical Interventions in Aging is an international, peer-reviewed journal focusing on evidence-based reports on the value or lack thereof of treatments intended to prevent or delay the onset of maladaptive correlates of aging in human beings. This journal is indexed on PubMed Central, MedLine, the American Chemical Society's 'Chemical Abstracts Ser-

\section{Dovepress}

vice' (CAS), Scopus and the Elsevier Bibliographic databases. The manuscript management system is completely online and includes a very quick and fair peer-review system, which is all easy to use. Visit http://www.dovepress.com/testimonials.php to read real quotes from published authors. 